\title{
ОПРЕДЕЛЕНИЕ ПРОДУКТИВНОСТИ РУДНО-МАГМАТИЧЕСКИХ СИСТЕМ КВИНУМ-КУВАЛОРОГСКОЙ НИКЕЛЕНОСНОЙ ЗОНЫ ПО ПЛОТНОСТНОЙ МОДЕЛИ (Камчатский срединный массив)
}

\author{
М. Д. Сидоров, В. Е. Кунгурова \\ ФГБУН Научно-исследовательский геотехнологический изентр ДВО РАН, \\ 2. Петропавловск-Камчатский \\ E-mail: smd52@mail.ru,kunwe@rambler.ru
}

\begin{abstract}
Методами количественной интерпретации аномального поля силы тяжести построена плотностная модель блока земной коры, включающего Квинум-Кувалорогскую никеленосную зону. В модели выделены массивные блоки, содержащие рудно-магматические системы, перспективные на медно-никелевые руды. Определены их форма, объем и металлогенический потенциал.
\end{abstract}

Ключевые слова: плотность, модель, интрузия, изоденса, никель, ресурсы.

DOI: 10.34078/1814-0998-2019-2-3-10

\section{ВВЕДЕНИЕ}

Известно, что «приближенно-количественная оценка массы полезного ископаемого, определенная при региональных металлогенических исследованиях сверх уже известных запасов и ресурсов,» составляет металлогенические ресурсы (Геологический словарь, 2011. С. 218) некоторого изученного объема геологической среды. Одним из способов такой приближенной оценки возможного количества металлов в рудовмещающих структурах может служить вычисление их объема по плотностной модели, созданной для блока коры, содержащего эти структуры. Плотность определяется по аномалиям силы тяжести в различных точках блока и формируется объемная модель ее распределения. В данной работе таким способом сделана попытка оценить металлогенический потенциал одной из рудоносных территорий Камчатской потенциально никеленосной провинции (Трухин и др., 2008) Квинум-Кувалорогской никеленосной зоны.

Камчатская потенциально никеленосная провинция (КНП) соответствует структуре срединного массива (известного также как Центрально-Камчатский кристаллический массив, Срединный Камчатский выступ метаморфических пород). Это крупное геологическое образование занимает южную часть Срединного хребта Камчатки. Сульфидные кобальт-медно-

(C) Сидоров М. Д., Кунгурова В. Е., 2019 никелевые руды генетически связаны с мелпалеоценовыми интрузиями дукукского габбронорит-кортландитового плутонического комплекса, которые распространены на территории массива. На севере и юге КНП известные рудопроявления никеля объединены в два рудных района: Шанучский и Дукукский соответственно (Трухин и др., 2008), а в центральной части провинции, в бассейне р. Колпакова, прогнозируется еще один никеленосный Колпаковский район (Сидоров, Степанов, 2006; Сидоров, 2009, 2015). Юго-западную часть Дукукского района занимает Квинум-Кувалорогская никеленосная зона, в осевой части которой находится Квинумский (Квинум-Степановский) глубинный разлом. Разлом ограничивает срединный массив с юга и имеет северо-западное простирание. С повышенной проницаемостью коры вдоль разлома связано внедрение интрузий никеленосного комплекса. В настоящее время в полосе шириной 15-20 км установлено более 30 проявлений и пунктов минерализации сульфидных медно-никелевых руд. Эта полоса и является никеленосной зоной. В аномальном поле силы тяжести зоне соответствует гравитационная ступень со сложной морфологией и амплитудой более 20 мГал (здесь и далее интенсивность аномалий приводится в условном уровне).

Интрузии никеленосного комплекса по размерам разделяются на две группы (Полетаев, 2004). Первая - линейные малые интрузии длиной до 1 км и мощностью от 1 м до первых 
десятков метров. Ко второй группе относятся относительно крупные (до 30 км²) интрузии. С малыми интрузиями-апофизами крупных массивов в их надынтрузивной зоне связаны рудные тела месторождения Шануч (Трухин и др., 2009б). Крупные массивы также несут обильную медно-никелевую минерализацию. Вместе с малыми интрузиями они образуют единые рудно-магматические системы. В КвинумКувалорогской зоне, на ее юго-восточном фланге, такую систему составляют интрузии группы Кувалорог. Кроме того, по геофизическим данным предполагается наличие подобных систем и в других частях зоны. Для определения пространственного положения рудно-магматических систем, их формы и объема была создана 3D модель плотности Квинум-Кувалорогской зоны.

Предпосылки, исходные данные и методика определения объемов. Определение объема рудно-магматических систем базируется на различии физических свойств интрузий никеленосного магматического комплекса и пород толщ, которые они прорывают. Вмещающей средой для интрузий являются отложения хейванской свиты и камчатской метаморфической серии. Преобладающую массу пород хейванской свиты составляют метапесчаники, метаалевролиты, филли-

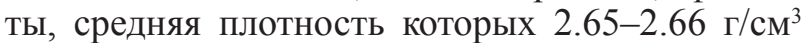
(Сидоров, Степанов, 2006). Мощность свиты в Квинум-Кувалорогской зоне более 2000 м, возраст ранне-позднемеловой (Сляднев и др., 2007). Отложения свиты через тектонический контакт залегают на породах камчатской метаморфической серии позднепротерозойского возраста. Серия представлена микрогнейсами и высокоглиноземистыми кристаллическими сланцами. Мощность образований около 1700 м (Там же). Плотность гнейсов изменяется от 2.57 до 2.65

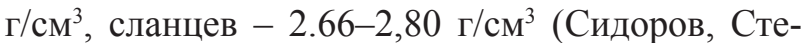
панов, 2006). Базит-ультрабазитовые породы никеленосных интрузий дукукского комплекса обладают плотностью в диапазоне от 2.85 до $3.1 \mathrm{r} / \mathrm{cm}^{3}$, что значительно превышает плотность окружающих пород. Благодаря большой избыточной плотности крупные интрузии никеленосного комплекса выделяются локальными максимумами аномалий Буге (Там же). Сложная морфология поля гравиметрической ступени в Квинум-Кувалорогской зоне, сильная изменчивость горизонтальных градиентов свидетельствуют о наличии в верхней части коры массивных неоднородностей, которыми являются интрузии базитов.

Локальные аномалии силы тяжести, связанные с интрузиями, выделены из наблюденного поля осреднением в скользящем окне с различными радиусами палетки (рис. 1). Амплитуда максимумов в Квинум-Кувалорогской зоне составляет 2-6 мГал. Для определения формы интрузий и занимаемого ими объема была построена воксельная (объемного изображения) плотностная модель участка земной коры в виде совокупности кубических ячеек определенной плотности.

Построение модели происходило поэтапно. Вначале были рассчитаны модели глубинных геолого-геофизических разрезов, пересекающих Квинум-Кувалорогскую зону в различных направлениях. В плоскости разрезов способом подбора (прямая задача) определена форма и теоретическая плотность сечений блоков геосреды. На этом этапе в качестве априорных данных были использованы стратиграфическая колонка, геологические карты, измерения плотности горных пород по образцам, результаты количественной интерпретации геофизических аномалий (нахождение особых точек).

Для глубоких горизонтов учтены данные сейсморазведки (MOB3) ближайших к району профилей (Нурмухамедов и др., 2016). Разрезы рассчитаны до глубины 50 км. Верхняя часть разрезов моделировалась наиболее детально, глубокие горизонты представлены в обобщенном виде. Далее в плоскости подобранных разрезов, в узлах квадратной сетки, определялись плановые координаты (X, Y, Z) и теоретические плотности. Шаг накладываемой сетки зависит от детальности (масштаба) подобранных разрезов и изменялся от десятков до сотен метров. Все это объединено в общую базу данных плотности (БДП), которую использовали для интерполяции 3D матрицы, изоплотностных поверхностей и вычислений объемов. Всего для модели Квинум-Кувалорогской зоны были использованы данные по 24 разрезам. Детальность воксельного изображения зависит от размера ребра элементарной ячейки. Для разных участков Квинум-Кувалорогской зоны он составил 2, 1 и 0.5 км. Более подробно методика опубликована в работах (Сидоров, 2015, 2016, 2017; Сидоров и др., 2016).

Плотностная воксельная модель служит основой для вычисления объема известных и прогнозируемых рудно-магматических систем. При моделировании использовали материалы среднемасштабных гравиметрических съемок, поэтому в модели нашли отражение относительно крупные интрузии никеленосного комплекса. Малые же интрузии для такой модели являются внемасштабными. Их доля в общем объеме учтена частично - в экзоконтакте крупных тел и в том случае, когда они являются проводниками между близко расположенными крупными массивами. Для нахождения местоположения, формы и объема блоков с интрузиями в модели были интерполированы поверхности с плотностью пород, слагающих никеленосные интрузии (рис. 2). 
В Квинум-Кувалорогской зоне наиболее изучена интрузия Кувалорог (Трухин и др., 2009а; Сидоров, Кунгурова, 2017). Строение и аналитика по этому массиву принимается в качестве эталонных данных для других, в том числе и неэродированных рудогенерирующих структур никеленосной зоны. Интрузия дифференцирована по составу от гранатовых диоритов до кортландитов с подавляющим преобладанием габброидов (габбро, нориты) (Трухин и др., 2009а). Наименьшей плотностью

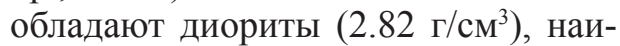
большей $\left(3.03\right.$ г $\left.\mathrm{cm}^{3}\right)$ - кортландиты и пироксениты. Диориты развиты преимущественно в зоне эндоконтакта, а кортландиты и пироксениты слагают маломощные тела внутри габброноритовой массы интрузии. Учитывая это, а также тектоническую раздробленность массива в качестве изоповерхности, описывающей предполагаемый контакт интрузии, можно принять изоповерхность с плотностью 2.86 г $/ \mathrm{cm}^{3}$, считая, что в охватываемом ею объеме заключены преимущественно интрузивные породы. Однако изучение Кувалорогской интрузии с поверхности показало наличие в ней крупных блоков вмещающих толщ (сланцев). В обнаженной части интрузива пробурено пять глубоких (500-900 м) вертикальных скважин.

Рис. 1. Схема перспективных локальных максимумов силы тяжести в КНП: 1 - выходы интрузий никеленосного комплекса; 2 - граница срединного массива; 3 - рудопроявления никеля; 4 - аномалии $\Delta \mathrm{g}$, связанные с крупными интрузиями дукукского комплекса: $a$ - за пределами, $\sigma$ - внутри Квинум-Кувалорогской никеленосной зоны. Цифрами обозначены номера аномалий в зоне, зубчатыми линиями - ее границы

Fig. 1. Scheme of perspective local gravity maxima in KNP: 1 - natural intrusion exposures of the nickel-bearing complex; 2 - boundary of the midian massif; 3 - nickel ore occurrences; $4-\Delta \mathrm{g}$ anomalies associated with large intrusions of the Dukuk complex: $a$ - beyond and $\sigma$ - within the Quinum-Kuvalor nickel-bearing zone. The numbers indicate the numbers of anomalies in the zone; jagged lines, its boundaries

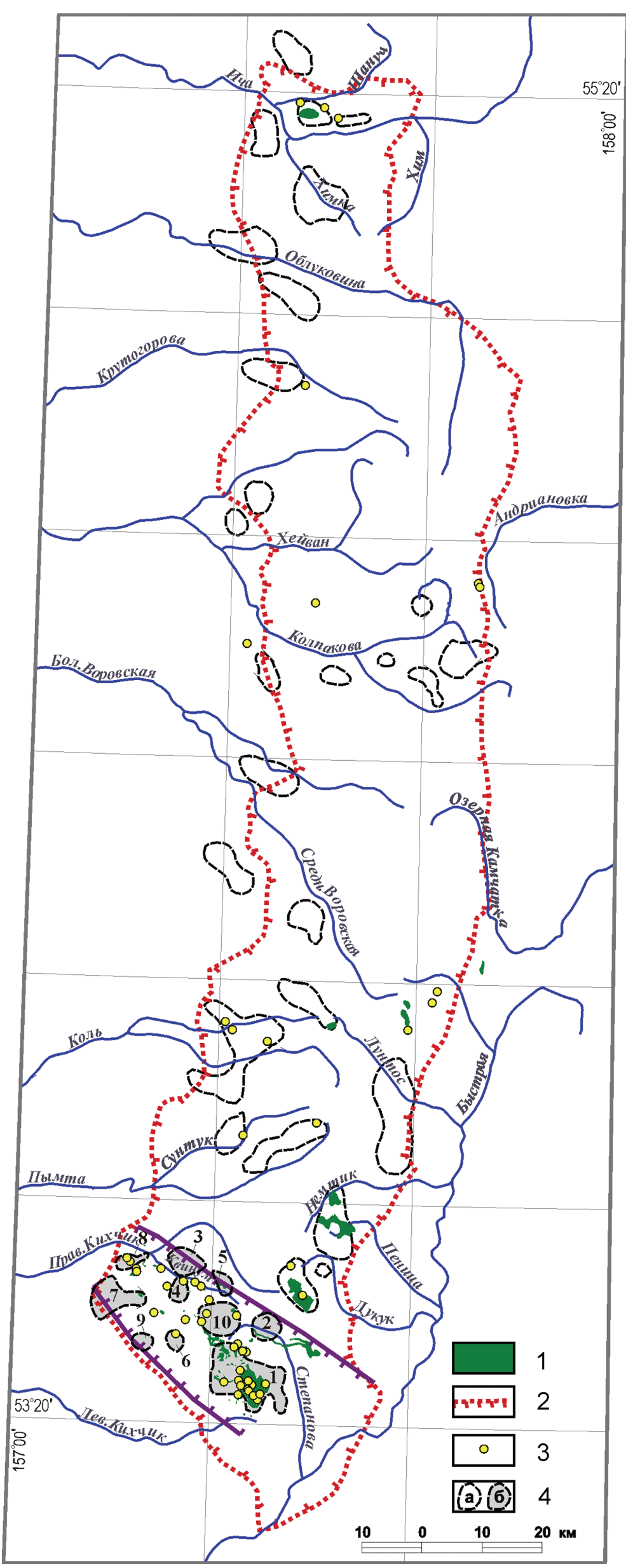



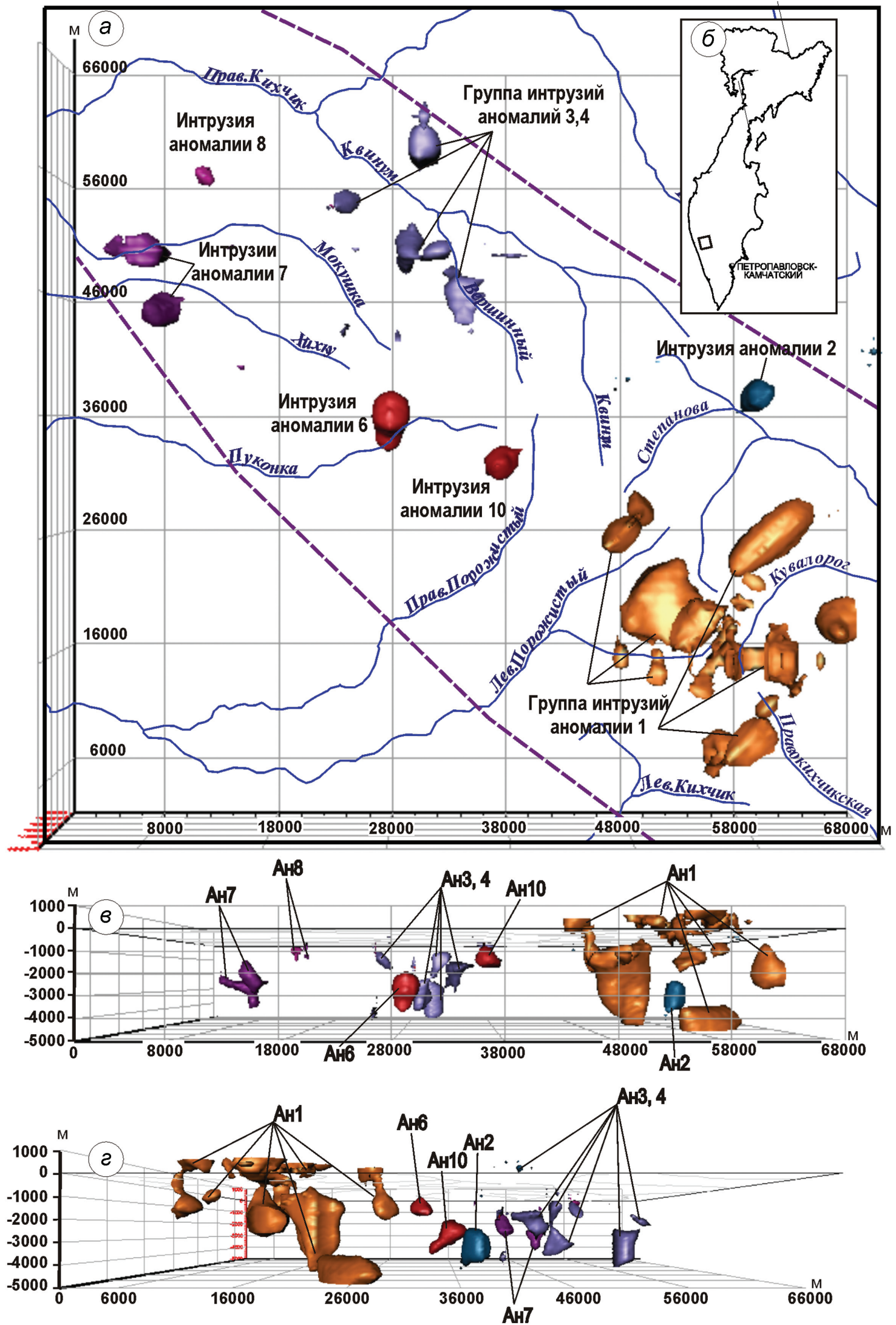

Puc. 2. Интрузии базитов в Квинум-Кувалорогской никеленосной зоне, выделенные по плотностной модели. Вид сверху (a), схема расположения (б) и боковые проекции с юга (в) и востока (2). Предполагаемые интрузии, оконтуренные по изоденсе 2.86 г/ $\mathrm{cm}^{3}$. Интрузии отдельных аномалий различаются цветом

Fig. 2. Basite intrusions in the Quinum-Kuvalorog nickel-bearing zone, identified by the density model: top view (a), layout ( 6 ) and side projections from the south (b) and the east (2). The assumed intrusions are contoured at isodence $2.86 \mathrm{~g} / \mathrm{cm}^{3}$. Intrusion of the individual anomalies are color-coded 
В разрезах скважин в среднем около $11 \%$ составляют породы, не относящиеся к интрузии. Эта величина введена в качестве поправки при расчете объемов (Сидоров, Кунгурова, 2017).

В западной части массива Кувалорог проведены прогнозно-геохимические исследования, по материалам которых определены средние содержания рудных компонентов в различных типах пород интрузии (Там же). Для нахождения средних содержаний никеля, меди и ко- бальта (табл. 1) использованы результаты полного спектрального полуколичественного анализа.

Жирным курсивом в таблице выделены средние содержания, использованные для определения металлогенического потенциала рудномагматических систем Квинум-Кувалорогской зоны. Для сравнения в табл. 2 приведены средние содержания этих же элементов в аналогичных породах земной коры.

Таблица 1. Содержание никеля, меди, кобальта в породах массива Кувалорог (Сидоров, Кунгурова, 2017) Table 1. Nickel, copper, and cobalt contents in the Kuvalorog Massif rocks (Sidorov, Kungurova, 2017)

\begin{tabular}{|c|c|c|c|c|c|}
\hline \multirow{2}{*}{ Тип породы } & \multirow{2}{*}{ Порода } & \multicolumn{3}{|c|}{$\begin{array}{l}\text { Среднее значение, \% } \\
\text { Разброс содержаний }\end{array}$} & \multirow{2}{*}{$\begin{array}{l}\text { Кол-во } \\
\text { проб }\end{array}$} \\
\hline & & $\mathrm{Ni}$ & $\mathrm{Cu}$ & Co & \\
\hline \multicolumn{6}{|c|}{ Породы без видимой сульфидной минерализации } \\
\hline $\begin{array}{l}\text { Ультрамафиты } \\
\text { основные }\end{array}$ & $\begin{array}{l}\text { Амфиболовые, оливинсодержащие } \\
\text { ортопироксениты }\end{array}$ & $0.004-0.04$ & $\underline{0.003-0.03}$ & $\frac{0.0126}{0.005-0.02}$ & 24 \\
\hline Основные & $\begin{array}{l}\text { Плагиоклаз-амфиболовое габбро, } \\
\text { биотит-амфиболовые габбронориты }\end{array}$ & $\frac{0.0281}{0.0015-0.07}$ & $\frac{0.0113}{0.003-0.05}$ & $\frac{0.0070}{0.002-0.02}$ & 73 \\
\hline $\begin{array}{l}\text { Ультрамафиты } \\
\text { основные }+ \\
\text { основные }\end{array}$ & $\begin{array}{l}\text { Все: амфиболовые, оливинсодер- } \\
\text { жащие плагиоклаз-флогопит- } \\
\text { амфиболовые орто-пироксениты } \\
\text { + плагиоклаз-амфиболовое габбро, } \\
\text { биотит-амфиболовые мелано- } \\
\text { габбронориты }\end{array}$ & $\frac{\underline{\mathbf{0 . 0 2 8 1}}}{0.0015-0.07}$ & $\frac{\underline{0.0131}}{0.003-0.05}$ & $\frac{\underline{0.0084}}{0.002-0.02}$ & 97 \\
\hline \multicolumn{6}{|c|}{ Породы с видимой сульфидной минерализацией - вкрапленной, прожилково-вкрапленной } \\
\hline $\begin{array}{l}\text { Ультрамафиты } \\
\text { основные }\end{array}$ & $\begin{array}{l}\text { Амфиболовые, оливинсодержащие } \\
\text { плагиоклаз-флогопит-амфиболовые } \\
\text { ортопироксениты с вкрапленностью } \\
\text { сульфидов } 1-10 \%\end{array}$ & $\frac{0.1429}{0.02-0.7}$ & $\frac{0.0457}{0.001-0.1}$ & $\frac{0.0119}{0.005-0.02}$ & 60 \\
\hline То же & $\begin{array}{l}\text { Лимонитизированные амфиболовые, } \\
\text { оливинсодержащие плагиоклаз-фло- } \\
\text { гопит-амфиболовые ортопироксе- } \\
\text { ниты }\end{array}$ & $\frac{0.1546}{0.004-0.7}$ & $\frac{0.0415}{0.003-0.4}$ & $\frac{0.0075}{0.0015-0.02}$ & 42 \\
\hline Основные & $\begin{array}{l}\text { Габбро, биотит-амфиболовые мелано- } \\
\text { габбронориты с вкрапленностью } \\
\text { сульфидов 3-10\% }\end{array}$ & $\frac{0.1577}{0.1-0.3}$ & $\frac{0.0216}{0.007-0.1}$ & $\frac{0.0114}{0.007-0.02}$ & 13 \\
\hline
\end{tabular}

Таблица 2. Кларки содержаний никеля, меди, кобальта в различных типах пород (Ронов и др., 1990) Table 2. Clarks of nickel, copper, and cobalt in different rock types (Ronov et al., 1990)

\begin{tabular}{|l|c|c|c|c|}
\hline \multirow{2}{*}{ Содержание, \% } & \multicolumn{4}{|c|}{ Типы горных пород } \\
\cline { 2 - 5 } & Ультраосновные & Основные & Средние & Кислые \\
\hline $\mathrm{Ni}$ & 0.1230 & $\mathbf{0 . 0 0 8 0}$ & 0.0061 & 0.0008 \\
\hline $\mathrm{Cu}$ & 0.0080 & $\mathbf{0 . 0 0 9 0}$ & 0.0060 & 0.0025 \\
\hline $\mathrm{Co}$ & 0.0080 & $\mathbf{0 . 0 0 3 0}$ & 0.0020 & 0.0010 \\
\hline
\end{tabular}




\section{ОБСУЖДЕНИЕ РЕЗУЛЬТАТОВ}

Рудно-магматические системы, выделенные по плотностной модели в Квинум-Кувалорогской зоне, показаны на рис. 2. Самой крупной является система аномалии 1 в районе массива Кувалорог. Она состоит из множества интрузивных блоков, расположенных в несколько ярусов, - от дневной поверхности до глубины 5 км и более. Интрузии других аномалий значительно уступают как по размерам, так и количеству отдельных фрагментов. На боковых проекциях видно, что практически все они находятся глубже уровня моря, а нижние кромки залегают в интервале от -4 до -4.5 км. Конечно, в действительности эти относительно крупные интрузии имеют глубинные подводящие каналы, но в масштабе модели они не выражаются, так же, как и малые тела в надынтрузивной зоне на удалении от них. Подсчет объемов и содержащихся в них металлов проведен для блоков, охватываемых изоповерхностью 2.86 г/ $\mathrm{cm}^{3}$ до глубины 3 км ниже уровня моря (табл. 3). ность. Подсчет проведен по «нормальным» породам (без видимой сульфидной минерализации), а в действительности количество металлов больше во всех системах, отмечаемых максимумами силы тяжести, и во всех системах могли локально концентрироваться сульфиды в виде рудных тел с промышленными объемами запасов никеля, меди и кобальта. Поэтому все рудномагматические системы Квинум-Кувалорогской зоны имеют хорошие перспективы на обнаружение таких тел.

Прогнозные ресурсы по категории $\mathrm{P}_{2}$ в Квинум-Кувалорогской зоне подсчитаны по рудным телам только шести рудопроявлений (Тундровое, Квинум 2, Ясное, Кортландитовое, Медвежье, Правокихчикское) и составляют, тыс. т: никеля - 476.11, меди - 134.25, кобальта - 8.61 (Сляднев и др., 2007). Очевидно, что изучение перспективных участков известных и предполагаемых рудно-магматических систем зоны на глубину может существенно увеличить прогнозные ресурсы.

Таблица 3. Продуктивность по металлам рудно-магматических систем Квинум-Кувалорогской никеленосной зоны по плотностной модели

Table 3. Productivity by metals in ore-magmatic systems of the Quinum-Kuvalorog nickel-bearing zone by the density model

\begin{tabular}{|c|c|c|c|c|c|c|c|}
\hline \multirow{3}{*}{ Магматическая система } & \multirow{3}{*}{$\begin{array}{l}\text { Объем, } \\
\text { км }^{3}\end{array}$} & \multicolumn{6}{|c|}{ Количество металлов в интрузиях, млн т } \\
\hline & & \multicolumn{3}{|c|}{$\begin{array}{c}\text { Средние (кларки) содержания } \\
\text { хим. эл. в земной коре (Ронов } \\
\text { и др., 1990) }\end{array}$} & \multicolumn{3}{|c|}{$\begin{array}{c}\text { Реальные средние содержания } \\
\text { хим. эл. в породах интрузии } \\
\text { Кувалорог }\end{array}$} \\
\hline & & $\mathrm{Ni}$ & $\mathrm{Cu}$ & Co & $\mathrm{Ni}$ & $\mathrm{Cu}$ & Co \\
\hline $\begin{array}{l}\text { Группа интрузий аномалии } 1 \\
\text { (Кувалорог) }\end{array}$ & 19.81 & 4.60 & 5.17 & 1.72 & 15.92 & 7.42 & 4.76 \\
\hline Аномалия 2 (р. Степанова) & 0.37 & 0.09 & 0.10 & 0.03 & 0.30 & 0.14 & 0.09 \\
\hline $\begin{array}{l}\text { Интрузии аномалий 3, } 4 \text { (р. Кви- } \\
\text { нум, руч. Вершинный) }\end{array}$ & 2.48 & 0.58 & 0.65 & 0.22 & 2.00 & 0.93 & 0.60 \\
\hline $\begin{array}{l}\text { Интрузии аномалий 6, } 10 \\
\text { (рр. Пуконка, Прав. Порожистый) }\end{array}$ & 1.51 & 0.35 & 0.39 & 0.13 & 1.22 & 0.57 & 0.36 \\
\hline $\begin{array}{l}\text { Интрузии аномалии } 7 \text { (рр. Мокуш- } \\
\text { ка, Хихку) }\end{array}$ & 1.07 & 0.25 & 0.28 & 0.09 & 0.86 & 0.40 & 0.26 \\
\hline $\begin{array}{l}\text { Интрузии аномалии } 8 \text { (руч. Тун- } \\
\text { дровый) }\end{array}$ & 0.05 & 0.01 & 0.01 & 0.00 & 0.04 & 0.02 & 0.01 \\
\hline ВСЕГО & 25.30 & 5.87 & 6.60 & 2.20 & 20.33 & 9.48 & 6.08 \\
\hline
\end{tabular}

Из табл. 1-3 видно, что продуктивность по металлам пород никеленосного комплекса по отношению к кларковым выше на порядок. Главный потенциал Квинум-Кувалорогской зоны сосредоточен в интрузиях, образующих аномалию 1. Это интрузия Кувалорог, в современном эрозионном срезе, ближайшие к ней малые интрузиисателлиты и тектонические отторженцы, а также крупные интрузивные блоки, предполагаемые на глубине и не имеющие выходов на поверх-

\section{ЗАКЛЮЧЕНИЕ}

Большая избыточная плотность интрузий никеленосного комплекса сравнительно к вмещающим толщам позволяет выявлять по аномалиям Буге массивные блоки, содержащие рудномагматические системы, перспективные на медно-никелевые руды. Форма, пространственное положение и объем, занимаемый системами, находятся методами количественной интерпретации поля силы тяжести, результатом которой является 
плотностная модель исследуемого участка земной коры.

В рудно-магматических системах можно приближенно определить теоретическое количество металлов (никель, медь, кобальт), основываясь на фактических концентрациях в породах известных обнаженных интрузий. Объем интрузий определяется по плотностной 3D модели, из которой выделяются блоки, охваченные изоповерхностью с плотностью, соответствующей средней плотности пород интрузии.

Количество металлов, найденное таким способом, можно принять за металлогенический ресурс сверх уже известных прогнозных ресурсов исследованного участка.

Для Квинум-Кувалорогской зоны до глубины 3 кмнижеуровня моря объем рудно-магматических

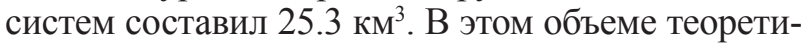
чески может содержаться не менее 20.33 млн т никеля, 9.48 млн т меди и 6.08 млн т кобальта.

\section{ЛИТЕРАТУРА}

Геологический словарь : в 3-х т.: изд. 3-е, перераб. и доП. / гл. ред. О. В. Петров. СПб. : Изд-во ВСЕГЕИ, 2011. Т. 2. С. 218.

Нурмухамедов А. Г., Недядько В. В., Ракитов В. А., Липатьев $M . C$. Границы литосферы на Камчатке по данным метода обменных волн землетрясений // Вестник КРАУНЦ, сер. Науки о Земле. 2016. № 1. Вып. 29. С. 35-52.

Полетаев $B$. A. Камчатская платиноидно-никеленосная зона - геология и рудоносность : автореф. дисс. ... канд. геол.-минер. наук. М., 2004. 22 с.

Ронов А. Б., Ярошевский А. А., Мигдисов А. А. Химическое строение земной коры и геохимический баланс главных элементов. М. : Наука, 1990. 180 с.

Сидоров М. Д. Воксельная модель плотности и прогнозирование никеленосных интрузий в Дукукском рудном районе (срединный массив, Камчатка) // Региональная геология и металлогения. 2017. № 70. C. $86-97$.

Сидоров М. Д. Геофизические критерии прогнозирования никеленосных интрузий в Камчатском сре- динном массиве // Чтения памяти акад. К. В. Симакова : тез. докл. Всерос. науч. конф. (Магадан, 25-27 нояб. 2009 г.). Магадан : СВНЦ ДВО РАН, 2009. С. 92-93.

Сидоров М. Д., Степанов В. А. Геофизические поля и никеленосность Камчатского срединного массива // Вестник КРАУНЦ, сер. Науки о Земле. П.-Камчатский. 2006. № 2. Вып. № 8. С. 140-150.

Сидоров М. Д., Кунгурова В. Е. Определение ресурсного потенциала металлов по плотностным моделям интрузий // Камчатка-5: Горный информ.-аналит. бюл. (науч.-техн. журн.). М. : Горная книга, 2017. Спец. выпуск 32. № 12. С. 121-137.

Сидоров М. Д. Плотностная модель Камчатского срединного массива // Камчатка-3: Горный информ.аналит. бюл. (науч.-техн. журн.). М. : Горная книга, 2016. Спец. выпуск 31. № 11. С. 83-87.

Сидоров М. Д. Плотностное моделирование магматических структур в Колпаковском перспективном никеленосном районе (срединный массив, Камчатка) // Тихоокеан. геология. 2015. Т. 34, № 3. С. 31-41.

Сидоров М. Д., Таскин В. В., Вешняков Н. А. Плотностные неоднородности в верхней коре Шанучского рудного района и проблема выявления невскрытых никеленосных интрузий (срединный массив, Камчатка) // Региональная геология и металлогения. 2016. № 65. С. 104-115.

Сляднев Б. И., Шаповаленко В. Н., Крикун Н. Ф. $u \partial p$. Государственная геологическая карта Российской Федерации. Масштаб 1:1000 000 (3-е поколение). Лист N-57 Петропавловск-Камчатский: объяснит. записка. СПб. : Изд-во СПб картфабрики ВСЕГЕИ, 2007. 206 с.

Трухин Ю. П., Степанов В. А., Сидоров М. Д. Камчатская никеленосная провинция // ДАН. 2008. Т. 418, № 6. C. $802-805$.

Трухин Ю. П., Сидоров М. Д., Степанов В. А., Кунгурова B. Е. Строение и никеленосность Кувалорогского базит-ультрабазитового массива // Известия высш. учеб. заведений. Геология и разведка. 2009а. № 6. C. $78-85$.

Трухин Ю. П., Степанов В. А., Сидоров М. Д., Кунгурова $B . E$. Шанучское медно-никелевое месторождение: геолого-геофизическая модель, состав и геохимия руд // Руды и металлы. 2009б. № 5. С. 75-81.

\title{
DETERMINING PRODUCTIVITY OF ORE-MAGMATIC SYSTEMS WITHIN THE QUINUM-KUVALOROG NICKEL-BEARING ZONE BY THE DENSITY MODEL (Kamchatka's Median Massif)
}

\author{
M. D. Sidorov, V. Ye. Kungurova \\ Geotechnological Center, FEB RAS, Petropavlovsk-Kamchatsky
}

The density model of the earth's crust block including the Quinum-Kuvalorog nickel-bearing zone was constructed by methods of quantitative interpretation of the anomalous gravity field. Massive blocks that contain ore-magmatic systems promising for copper-nickel ores are identified in the model. Their shape, volume, and metallogenic potential are determined.

Keywords: density, model, intrusion, isodence, nickel, resources. 


\section{REFERENCES}

Geological Dictionary, 2011, In 3 Vol., $3^{\text {rd }}$ Edition, Rev. and Add., Ed. O. V. Petrov, St. Petersburg, Izd-vo VSEGEI, 2, 218 [In Russian].

Nurmukhamedov, A.G.; Nedyadko, V.V.; Rakitov, V.A.; Lipatyev, M. S., 2016, The Lithosphere Boundaries in Kamchatka by Data from the Earthquake Converted-Wave Method (Ecwm), Bulletin of Kamchatka Regional Association "Educational-Scientific Centre", Earth Sciences, Petropavlovsk-Kamchatsky, Iss. 1, 29, 35-52 [In Russian].

Poletaev, V. A., 2004, Kamchatka Platinoid-NickelBearing Zone - Geology and Mineralization, Author's Abstract, Diss. Cand. Sci. (Geology \& Mineralogy), Moscow [In Russian].

Ronov, A. B.; Yaroshevsky, A. A.; Migdisov, A. A., 1990, Chemical Structure of the Earth's Crust and the Geochemical Balance of Major Elements, Moscow, Nauka [In Russian].

Sidorov, M. D., 2009, Geophysic Criteria for Forecasting Nickeliferous Intrusions in Kamchatka's Median Massif, In Memory of Academician K. V. Simakov, Materials of All-Russia Conference (Magadan, 25-27 November 2009), Magadan, NESC FEB RAS, 92-93 [In Russian].

Sidorov, M. D., 2015, Density Modeling of Magmatic Structures in the Kolpakov Perspective Nickeliferous District (Median Massif, Kamchatka), Russian Journal of Pacific Geology, 34, 3, 31-41 [In Russian].

Sidorov, M. D., 2016, Density Model of Kamchatka's Median Massif, Mining Informational and Analytical Bulletin (Scientific and Technical Journal), Kamchatka-3, Sp. Iss. 31, 11, 83-87 [In Russian].

Sidorov, M. D., 2017, Voxel Density Model and Forecasting Nickeliferous Intrusions in the Dukuk Ore District (Median Massif, Kamchatka), Regional Geology and Metallogeny, 70, 86-97 [In Russian].
Sidorov, M. D.; Kungurova, V. Ye., 2017, Defining the Resource Potential of Metals by Intrusion Density Models, Mining Informational and Analytical Bulletin (Scientific and Technical Journal), Kamchatka-5, Moscow, Gornaya Kniga, Sp. Iss. 32, 12,121-137 [In Russian].

Sidorov, M. D.; Stepanov, V. A., 2006, Geophysical Fields and Nickel Content of the Median Massif, Kamchatka, Bulletin of Kamchatka Regional Association "Educational-Scientific Centre”, Earth Sciences, 2, 8, 140-150 [In Russian].

Sidorov, M.D.; Taskin, V. V.; Veshnyakov, N. A., 2016, Density Irregularities in the Upper Crust of the Shanuch Ore District and the Problem of Detecting Unopened Nickel Intrusion (Median Massif, Kamchatka), Regional Geology and Metallogeny, 65, 104-115 [In Russian].

Slyadnev, B. I.; Shapovalenko, V. N.; Krikun, N. F., Poletaev, A. A.; Rothman, K. V.; Sidorenko, V. I.; Sidorov, E. G.; Surikov, S. N.; Khasanov, Sh. G., 2007, State Geological Map of the Russian Federation, Scale 1:1 000000 ( $3^{\text {rd }}$ Generation), Sheet N-57, Petropavlovsk-Kamchatsky, Explanatory Note, St. Petersburg, Izd-vo SPb Kartfabriki VSEGEI [In Russian].

Trukhin, Yu.P.; Stepanov, V. A.; Sidorov, M. D., 2008, Kamchatka Nickeliferous Province, Doklady Akademiyi Nauk, 418, 6, 802-805 [In Russian].

Trukhin, Yu. P.; Stepanov, V. A.; Sidorov, M. D.; Kungurova, V. Ye., 2009, Shanuch Copper-Nickel Deposit: Geological and Geophysical Model, Composition, and Geochemistry of Ores, Rudy i Metally, 5, 75-81 [In Russian].

Trukhin, Yu. P.; Stepanov, V. A.; Sidorov, M. D.; Kungurova, V. Ye., 2009, Structure and Nickel Content of the Kuvalorog Basite-Ultrbasite Massif, Izvestiya Vysshikh Uchebnykh Zavedeniy, Geologiya i Razvedka, 6, 78-85 [In Russian]. 